\title{
Supercooling Points of Murgantia histrionica (Hemiptera: Pentatomidae) and Field Mortality in the Mid-Atlantic United States Following Lethal Low Temperatures
}

\author{
Anthony S. DiMeglio, ${ }^{1,2}$ Anna K. Wallingford, ${ }^{3}$ Donald C. Weber, ${ }^{4}$ Thomas P. Kuhar, $^{1}$ \\ and Donald Mullins ${ }^{1}$
}

1Department of Entomology, Virginia Tech, 170 Drillfield Drive, Blacksburg, VA 24061 (harlequinbugs@vt.edu; tkuhar@vt.edu; mullinsd@vt.edu), ${ }^{2}$ Corresponding author, e-mail: harlequinbugs@vt.edu, ${ }^{3}$ Department of Entomology, Cornell University, 630 W. North St., Geneva, NY 14456 (annawllngfrd@gmail.com), and ${ }^{4}$ Invasive Insect Biocontrol and Behavior Lab, USDA Agricultural Research Service, BARC-West 007, Beltsville, MD 20705 (Don.Weber@ars.usda.gov)

Received 24 April 2016; Accepted 28 June 2016

\begin{abstract}
The harlequin bug, Murgantia histrionica (Hahn), is a serious pest of brassicaceous vegetables in southern North America. While this insect is limited in its northern range of North America, presumably by severe cold winter temperatures, specific information on its cold hardiness remains unknown. We determined the supercooling points (SCPs) for Maryland and Virginia adult populations and found no significant difference among these populations. SCPs were similar for adults $\left(\bar{X}=-10.35^{\circ} \mathrm{C} ; \sigma_{X}=2.54\right)$ and early and late instar $\left(\bar{X}=-11.00^{\circ} \mathrm{C} ; \sigma_{X}=4.92\right)$ and between adult males and females. However, SCPs for first instars $\left(\bar{X}=-21.56^{\circ} \mathrm{C} ; \sigma_{X}=1.47\right)$ and eggs $\left(\bar{X}=-23.24^{\circ} \mathrm{C} ; \sigma_{X}=1.00\right)$ were significantly lower. We also evaluated field survival of overwintering harlequin bug adults during extreme cold episodes of January 2014 and January 2015 , which produced widespread air temperatures lower than $-15^{\circ} \mathrm{C}$ and subfreezing soil temperatures in the Mid-Atlantic Region. After the 48-h episode in 2014, bug mortality in exposed field sites averaged $88 \%$, compared to $<5 \%$ mortality of bugs sheltered in an unheated greenhouse (recorded minimum temperature $4.4^{\circ} \mathrm{C}$ ). After the 2015 episode, $\sim 80 \%$ of adults that were established in the field the previous November and then sheltered in an unheated garage during the episode, died, in contrast to $96 \%$ mortality in exposed field sites. Our results provide new information on $M$. histrionica overwintering biology, and thermal limitations to its distribution, which leads to improved predictive capabilities to forecast pest severity.
\end{abstract}

Key words: supercooling point, lethal low temperature, field survival, polar vortex

Murgantia histrionica (Hahn), native to Central America (Paddock 1918), has expanded widely into the United States since it was first collected in Texas in 1864 (Paddock 1915). With two to three generations per year (Wallingford et al. 2011), this key pest of Brassica spp. can quickly infest farms, damaging vegetables such as cabbage, broccoli, collards, radishes, and kale. Occasional extreme winter events have historically suppressed its distribution in northern latitudes just south of the Mason-Dixon Line (Walker and Anderson 1933). A combination of physiological and behavioral adaptations allow for overwintering insects, like $M$. histrionica, to survive a range of winter extremes common in temperate regions (Duman et al. 1991). As Venette et al. (2010) explained, understanding implications of insect cold-hardiness can help us better understand pest severity and outbreaks and forecast geographic distribution and potential range expansions.

Extreme winter weather events, such as sudden shifts in Arctic air currents, can have significant effects on temperate insect pest abundance and distributions (Bale and Hayward 2010). A recordbreaking cold air mass blanketed much of the United States with a high pressure system propagating from the Arctic in mid-February 1899 (Kocin et al. 1988). Sanderson (1908) reported significant reductions in M. histrionica populations following this bitterly cold Arctic air mass, when minimum temperatures reached $-28.9^{\circ} \mathrm{C}$ in Ohio and $-26.1^{\circ} \mathrm{C}$ in Washington D.C. (Sanderson 1908), and $-15^{\circ} \mathrm{C}$ in the Carolinas (Kocin et al. 1988). Although field mortality of M. histrionica was not formally measured before and after this winter event, the 1899 North American winter serves as anecdotal evidence of the negative impact of extreme low temperatures on $M$. histrionica abundance.

Events of prolonged subfreezing temperatures may occur more frequently in the southeastern United States than in the past decades due to altered atmospheric thermal gradients between northern and mid-latitudes (Frauenfeld and Davis 2003, Limpasuvan et al. 2004, Francis and Vavurs 2012). Therefore, it is important to understand 
how freeze-avoiding insects are affected by potentially lethal lower temperatures (Elsey 1993), especially for temperate insects in a changing climate (Bradshaw 2010).

Saulich and Musolin (2012) reviewed literature and experimental data on diapause in 43 Pentatomidae species overwintering in temperate climates, although did not include M. histrionica, and concluded that the majority of species undergo facultative imaginal diapause-that is, extrinsic cues such as temperature and photoperiod trigger arrested development in adults. Murgantia histrionica undergo homodynamic development, and therefore activity during winter months is primarily dictated by temperature; in mild winters they are active (Thomas 1915, Paddock 1915, 1918) with feeding, copulation, and oviposition possible (Sullivan and Brett 1974).

Diapause and categories of cold-hardiness occur conjointly. Salt (1961) and Lee (1991) divided cold-hardiness of insects into three groups: chilling intolerant, freezing tolerant, and freeze avoidant. According to Sinclair et al. (2003), most temperate insects in the Northern Hemisphere are freeze intolerant. Internal ice formation is lethal to this group of insects; thus, they are often classified as freeze avoidant (Lee 1991). Hemolymph will instantaneously crystallize within a range of temperatures; the temperature at which this occurs is referred to as the supercooling point (Baust and Rojas 1985).

Supercooling points vary in insects according to body size, water content, dissolved solutes such as sugars and ions, and composition of amino acid and proteins in the hemolymph (Lee 2010). The supercooling point is conventionally measured thermoelectrically to detect the exotherm resulting from the latent heat of fusion. Measuring supercooling points for freeze avoiding insects yields a concrete value for beginning to understand cold hardiness (Carrillo et al. 2004).

Elsey (1993), without providing the recorded range, approximated a supercooling point of Nezara viridula (L.) (Hemiptera: Pentatomidae) at $-11^{\circ} \mathrm{C}$ with thermocouples in direct contact with their abdomen, insulated by a polystyrene box and held in a $-20^{\circ} \mathrm{C}$ reach-in freezer. There was no difference of supercooling points between males and females, nor between diapausing and nondiapausing adults. However, the author did note that N. viridula had a much higher SCP than two other pentatomids, M. histrionica at $-14.7^{\circ} \mathrm{C}$ and Euschistus servus (Say) at $-15.0^{\circ} \mathrm{C}$. Unfortunately, since E. servus and M. histrionica SCPs were sourced from unpublished results, the important details (e.g., sample size, source population, diet, and environmental preconditioning) are unknown.

Our research investigated supercooling points of M. histrionica, by life stage and sex, as well as field mortality during extreme cold weather episodes in the Mid-Atlantic United States. If M. histrionica are truly freeze intolerant, the distribution of supercooling points within a sample population will correspond to observed field mortality during extreme cold weather episodes. We assayed field mortality in wild populations of M. histrionica in Beltsville, MD, and Blacksburg, VA, during extreme winter weather events of January 2014 and January 2015, and related the observed temperatures and population impacts to SCPs determined in the lab. Egg SCPs were determined thermoelectrically, which we then related to hatch rates after exposure to subfreezing temperatures in an effort to determine a range of lethal lower temperatures for the species.

\section{Materials and Methods}

\section{Polar Vortex Climate Observations}

The extreme cold "polar vortex" episodes in Beltsville, MD, and Blacksburg, VA, were documented using climate monitoring instruments (Decagon Devices, Pullman, WA) positioned within overwintering habitats. For both 2014 and 2015, microclimate sensors were installed to record temperature at $1 \mathrm{~cm}$ soil depth, and air within the plant canopy $(0.05 \mathrm{~m})$ and above $(1 \mathrm{~m})$ the $\mathrm{M}$. histrionica overwintering habitat. After "polar vortex" episodes, both control and exposed bugs were monitored for $3 \mathrm{~d}$ at ambient temperature $\left(20-25^{\circ} \mathrm{C}\right)$, to visually characterize external ice formation on insect cuticle, and to record activity and mortality.

\section{Insects}

\section{SCP Determination}

M. histrionica adults were collected in early September 2013 in Beltsville, MD ( $39^{\circ} 1^{\prime} 37.37^{\prime \prime} \mathrm{N}, 76^{\circ} 56^{\prime} 0.96^{\prime \prime} \mathrm{W}$; elevation $\left.=38 \mathrm{~m}\right)$, and were used to start a colony, which was maintained on potted collards (Brassica oleracea group acephala cv. 'Champion' and 'VATES') at $25^{\circ} \mathrm{C}$ and a photoperiod of 16:8 (L:D) h. Only bugs from generations F1-F5 were used in these experiments. Bugs were carefully isolated from colonies in ventilated plastic containers with an excised collard leaf, and held at ambient temperature $\left(20-25^{\circ} \mathrm{C}\right)$ up to $5 \mathrm{~h}$ prior to SCP determination. Eggs laid in these colonies within the previous $24 \mathrm{~h}$ were shipped overnight to Geneva, NY $\left(42^{\circ} 52^{\prime} 38.40^{\prime \prime} \mathrm{N}, 77^{\circ} 00^{\prime} 26.14^{\prime \prime} \mathrm{W}\right.$; elevation=188 m) where egg clusters and first instars that hatched after arrival were assayed for SCPs. An additional field-collected population in early April 2014 from Painter, VA $\left(37^{\circ} 35^{\prime} 04.61^{\prime \prime} \mathrm{N}, 75^{\circ} 49^{\prime} 15.64^{\prime \prime} \mathrm{W}\right.$; elevation $=9$ $\mathrm{m})$, was tested with individuals acclimated $\left(25^{\circ} \mathrm{C}\right.$ and a photoperiod of $16: 8$ [L:D] h) for at least $14 \mathrm{~d}$ following the same procedures.

\section{Field Survival}

In late September 2013, wild M. histrionica adults collected on summer cultivated collards were isolated in aluminum mesh cages used by Cabrera Walsh et al. (2016) over patches of volunteer cultivated Brassica species. The habitat also included wild grasses and weeds, which provided overwintering refuges. Bug densities per cage did not exceed 500 individuals per square meter. Three days prior to the extreme cold episode, caged bugs were recovered and held at $\sim 10^{\circ} \mathrm{C}$ in an unheated greenhouse for $24 \mathrm{~h}$ to segregate active versus inactive, presumably dead, adults. Active adults were then returned to the field $20 \mathrm{~h}$ prior to the extreme cold episode to allow bugs to move unhindered in overwintering habitat. A sample of 75 field collected adults were exposed to extreme winter weather confined within $0.15 \mathrm{~m}^{2}$, and, as a control, 50 adults from the same population were sheltered in an unheated glasshouse where minimum temperatures reached $4.4^{\circ} \mathrm{C}$ and never exceeded $15.5^{\circ} \mathrm{C}$.

\section{Field Survival}

Randomly selected $M$. histrionica adults from summer cultivated collards were isolated in November 2014 from Kentland Farm, Blacksburg, VA $\left(37^{\circ} 12^{\prime} 06.73^{\prime \prime} \mathrm{N}, 80^{\circ} 33^{\prime} 52.27^{\prime \prime} \mathrm{W}\right.$; elevation $\left.=517 \mathrm{~m}\right)$, in groups of 10 individuals on large collard plants (leaves radiating out $20 \mathrm{~cm}$ from the stem). Twelve isolated groups were randomly arranged in the collard plot. Bugs were confined on plants with 18.9-liter paint strainer bags (Trimaco, Morrisville, NC) and restricted with a plastic zip tie at the base of the plant, to allow bugs to naturally move unhindered to all portions of the plant.

In the afternoon, prior to the January 2015 "polar vortex" episode, 6 of the 12 groups of confined adults were randomly selected and collected by severing the base of the collard plant below the mesh bag, and transported to an unheated garage to shelter them from extreme subfreezing temperatures (indoor temperatures ranged 
from $1.4^{\circ} \mathrm{C}$ to $7.0^{\circ} \mathrm{C}$ ). The other six groups remained on plants in the field to serve as our treatment group.

\section{Egg Hatch Rate Following Cold Treatments}

Insect cultures were reared from field collected adults (sourced early Sept. 2015, Blacksburg, VA) on potted collards (B. oleracea var. VATES or Champion) in summer conditions in a climate controlled greenhouse $\left(25-30^{\circ} \mathrm{C}\right.$, providing supplemental light at a photoperiod of 16:8 [L:D] h). Eggs from the parental generation were collected $24-48 \mathrm{~h}$ after laying, and then held at ambient temperatures $\left(20-25^{\circ} \mathrm{C}\right)$ before conducting experiments described below.

\section{Lethal Low Temperature Determination Methods SCPs of Adults and Early and Late Instars}

Supercooling points of adults and nymphs were measured with braided coiled copper-constantan thermocouples (Hanson and Venette 2013) on the ventral abdominal segments, with the syringe plunger gently immobilizing the bug. Thermocouples were attached to a multichannel data logger (USB-TC, Measurement Computing, Norton, MA) recording at $0.5 \mathrm{~Hz}$ and logged by using Tracer-DAQ software (Measurement Computing). Individual supercooling points were determined as the minimum temperature reached before the dramatic increase in temperature, which is associated with the exotherm from latent heat of fusion.

In 2013, we modified a protocol developed by Carrillo et al. (2004), where individual bugs and braided thermocouple were confined in a $35-\mathrm{ml}$ syringe that was placed at the center of a 0.19 by 0.19 - by $0.19-\mathrm{m}$ expanded polystyrene cube (Foam-Control Type IX, Cellofoam North America Inc., Winchester, VA) and then into a $-80^{\circ} \mathrm{C}$ freezer for a projected cooling rate of $-0.5^{\circ} \mathrm{C} \mathrm{min}^{-1}$, with a realized cooling rate of $-0.75 \pm 0.35^{\circ} \mathrm{C} \mathrm{min}^{-1}$. Each assay was run until internal temperature of the cube reached $-30^{\circ} \mathrm{C}$.

One hour prior to SCP measurements for adults and second through fifth instars, bugs were weighed to the nearest $\mu$ g (Ohaus, Explorer Pro, Parsippany, NJ). After SCP determination, each bug was stored at $-25^{\circ} \mathrm{C}$ until subsequent oven drying. Bugs were dried at $65^{\circ} \mathrm{C}$ for $48 \mathrm{~h}$ and weighed to determine water content.

\section{SCP of Eggs and First Instars}

Supercooling points for egg masses and groups of recently hatched M. histrionica were estimated using a method modified from Mills et al. (2006) to detect the exotherms from spontaneous freezing. Unhatched egg masses ( $36 \pm 12 \mathrm{~h}$ since oviposition to represent our egg census) or recently hatched masses ( $\sim 24 \mathrm{~h}$ to represent our first instars census) were moved to thermal electric modules (TEM), trays of 10 wells holding Peltier plates ( 4 by $4 \mathrm{~cm}$ ). The TEMs were then moved to a programmable freezer (Thermal Product Solutions, Williamsport, PA) and held $0^{\circ} \mathrm{C}$ for $1 \mathrm{~h}$, to bring plate temperature down from room temperature. The temperature was then reduced at a rate of $0.5^{\circ} \mathrm{C}$ $\min ^{-1}$ to $-40^{\circ} \mathrm{C}$ and then held at $-40^{\circ} \mathrm{C}$ for $1 \mathrm{~h}$ to ensure all plates reached this lower temperature. Peltier plates detect temperature gradients on either side of the plate and convert the thermal signals to voltage outputs recorded by a Keithley Multimeter Data Acquisition System (model 2700-DAQ-40; Keithley Instruments, Cleveland, OH) at the same time that temperature is recorded at the plate surface by thermistors (model 44212; YSI, Dayton, $\mathrm{OH}$ ) in one of the wells of each TEM. A visible peak in voltage $(\mathrm{mV})$ graphed over time indicated an exotherm and the corresponding temperature recorded at the plate surface indicates the temperature at which ice formation occurred. The output from at least one empty well in each TEM served as a control to compare voltage amplitude.

\section{Egg Hatches After Cold Treatments}

We selected three subfreezing temperatures of $-5,-16$, and $-23^{\circ} \mathrm{C}$ to test for egg mortality under simulated field conditions (i.e. rates of cooling and warming mirrored trends observed during winter weather anomalies of 2014 and 2015). Temperatures were selected based on observed $M$. histrionica egg SCP of $-23^{\circ} \mathrm{C}$, thermal minimum during extreme cold episodes $\left(-16^{\circ} \mathrm{C}\right)$, and typical winter low temperatures $\left(-5^{\circ} \mathrm{C}\right)$ in Mid-Atlantic United States. Egg masses up to $48 \mathrm{~h}$ old were obtained from adult $M$. histrionica that were collected in early fall from collards near Blacksburg, VA, and held in a greenhouse under conditions mentioned above.

Eggs were subjected to subfreezing temperatures in 5-ml centrifuge tubes (MacroTubes, Orange County, CA) sealed to exclude liquid with Parafilm (Bemis NA, Neenah, WI). Sealed tubes with egg masses were submerged in 50/50 water and ethanol mixture in a refrigerated water bath (Fisher Scientific Isotemp, Waltham, MA) where the temperature declined at a rate of $-0.16^{\circ} \mathrm{C} \mathrm{min}{ }^{-1}$, holding at treatment temperature for $30 \mathrm{~min}$ before returning at a rate of $2.00^{\circ} \mathrm{C} \min ^{-1}$ temperature to $25^{\circ} \mathrm{C}$. Control eggs $(n=171)$ were held in Parafilm-sealed centrifuge tubes at ambient temperature (20$25^{\circ} \mathrm{C}$ ). After each cold treatment, all treatment and control egg masses were isolated in Petri dishes with filter paper in a growth chamber held at $28^{\circ} \mathrm{C}$ at $50-80 \% \mathrm{RH}$ and a photoperiod of $16: 8$ (L:D) h. Successful egg hatches were tallied by counting the number of nymphs after $20 \mathrm{~d}$; Abbott's formula was used to correct for control mortality (Abbott 1925).

\section{Statistics}

Data were analyzed with one-way ANOVAs, Student's t-test, Tukey-Kramer HSD, and Fisher's exact test, using R version 3.2.2 ( $\mathrm{R}$ Core Team 2015) in RStudio version 0.99.484 (RStudio 2015), and analyzed with an $\alpha$ value set at 0.05 .

\section{SCP Comparisons}

The SCPs for adult bugs collected from Painter, VA, and Beltsville, $\mathrm{MD}$, were inspected for normality using histogram analysis to measure skewness and kurtosis, followed by a Levene Test for homogeneity of variance among locations and sex. We assumed Gaussian processes without violations within a histogram analysis (skewness $=0.422$ and 1.21, and kurtosis $=1.93$ and 4.01 for Painter and Beltsville, respectively) and variance between groups was homogenous $(F=0.2055 ; \mathrm{df}=3,33 ; P=0.8919)$.

\section{Predicted Supercooling Point Distributions}

The R package fitdistrplus (Delignette-Muller et al. 2015) was used to model adult supercooling point distributions. Within this package, a Cullen-and-Frey Graph was used to approximate theoretical distribution using observed supercooling points. Based on Akaike information criterion, a gamma distribution model was used to predict cumulative supercooling points.

\section{Results and Discussion}

\section{Field Survival}

\section{Maryland 2014}

Soil surface temperatures where the exposed adults were found below plant litter reached a minimum of $-3.9^{\circ} \mathrm{C}$ during the episode, whereas air temperature reached a minimum of $-15.8^{\circ} \mathrm{C}$ (Fig. 1A). Because of this thermal gradient, exposed bugs likely experienced a range of subfreezing temperatures, and cooling rates. Nonetheless, these conditions were lethal to $M$. histrionica. Compared to 

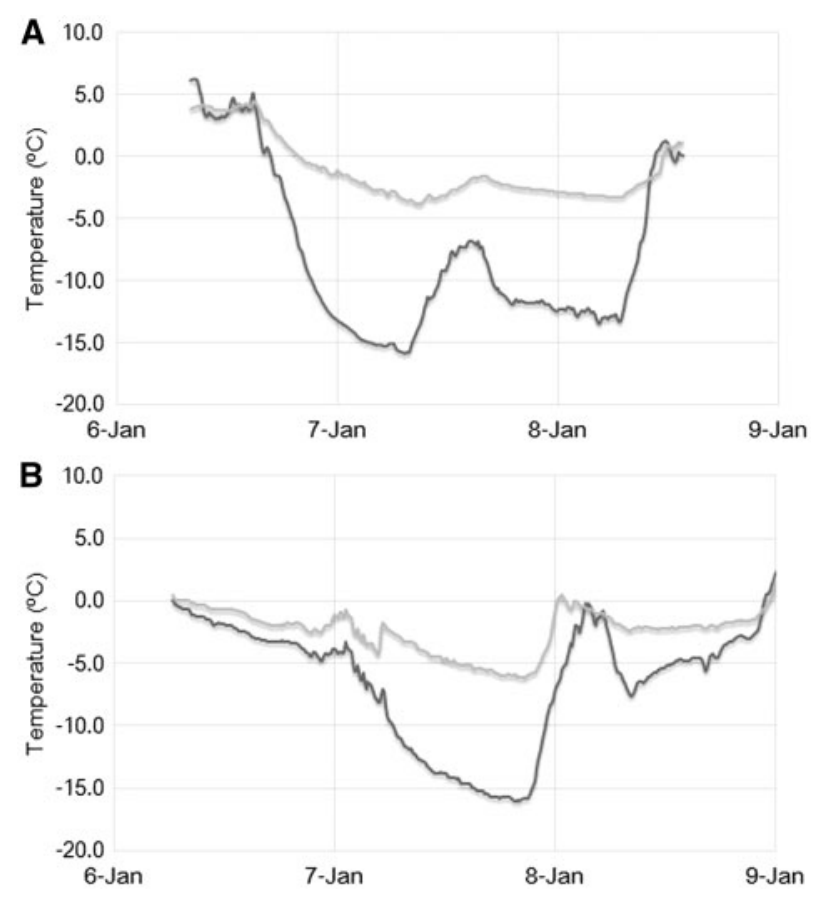

Fig. 1. Soil and air temperature readings from 2014 and 2015 "Polar Vortex" episodes occurring in early January. In both panels dark black lines represent air temperature measurements, whereas light gray indicate soil surface temperatures. All labeled dates (date and month) are delimited at 12 a.m. (0:00 hours). Top panel (A): In 2014 soil surface temperatures where adults were found reached a minimum of $-3.9^{\circ} \mathrm{C}$, and air temperature $-15.8^{\circ} \mathrm{C}$. Bottom panel (B): In 2015 soil surface temperatures reached a minimum of $-6.2^{\circ} \mathrm{C}$ and air temperature $-16.0^{\circ} \mathrm{C}$.

sheltered group held in a small greenhouse (recorded minimum temperature $4.4^{\circ} \mathrm{C}$ ), the mortality in the exposed group was significant (Fisher's exact test, $P<0.0001)$ with 66 of $75(88 \%)$ compared to 2 of $50(4 \%)$ mortality. However, presence of ice crystals on 8 January 2014 was significantly correlated with mortality (Fisher's exact test, $P=0.00089$ ); only $2 \%$ of bugs ( 1 of 48 ) survived if surrounded by ice, but almost $30 \%$ ( 8 of 27 ) of those not showing external ice were still alive several days after the cold-temperature episode.

\section{Virginia 2015}

In the field, soil surface temperatures reached a minimum of $-6.2^{\circ} \mathrm{C}$ and air temperature rapidly fell to a minimum of $-16.0^{\circ} \mathrm{C}$ (Fig. 1B). Control bugs sheltered in an unheated garage were exposed to a minimum ambient temperature of $1.4{ }^{\circ} \mathrm{C}$ during the event. Field exposed bugs experienced high mortality at 26 of 27 ( $~ 96 \%$ ), but according to Fisher's exact test, $P=0.0620$, field mortality was not significantly higher than the control group mortality at 23 of $29(\sim 79 \%)$ dead after the cold weather event. However, since these bugs were isolated in the field in early November 2014, cumulative mortality is unlikely related to the 2015 weather event we assayed, but more likely related to repeated cold weather events because they were exposed to winter conditions longer than the 2014 outdoor group.

\section{Supercooling Point Comparison and Egg Hatch Rates}

Supercooling points in a small number of our observations were at least two standard deviations from than their means, most likely due to fecal or other material with high water content; accordingly, we

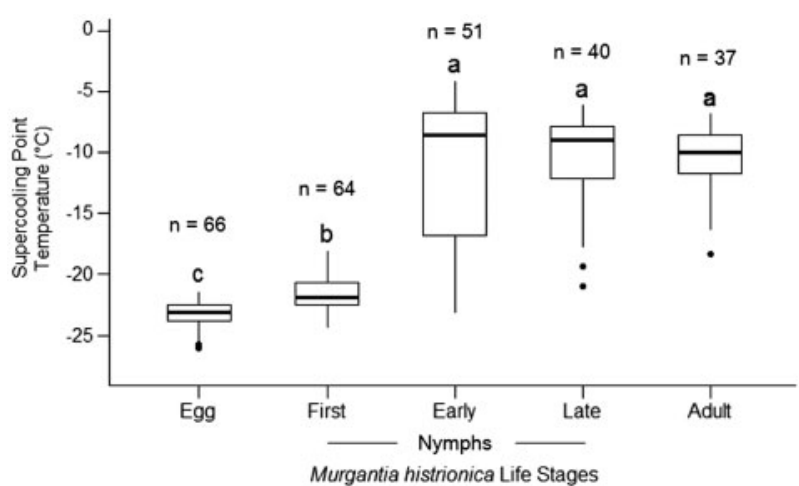

Fig. 2. Comparison of supercooling points observed for $M$. histrionica among life stages. One-way ANOVA indicates significant differences among life stages $(P<0.001)$. Means for life stages with same letter do not differ according to Tukey-Kramer HSD. Box plots show mean $\pm 25 \%$ and $\pm 40 \%$ of sample with outliers as dots.

censored six outlying observations ranging from $-2.15^{\circ} \mathrm{C}$ to $-3.74^{\circ} \mathrm{C}$ just as Cira et al. (2016) eliminated similar outliers in their study of Halyomorpha halys (Stål).

A Student's t-test revealed no significant effect of location $(t=1.0876 ; \mathrm{df}=35 ; P=0.2842)$ and, therefore, SCP of adults from Beltsville, MD, and Painter, VA, were pooled as one group labeled "adults" in all further analyses. SCP values did not correlate with total water content $(t=0.55849 ; \mathrm{df}=126 ; P=0.5775$, Pearson's $R=0.04969314$ ) among adults and second through fifth instars, and, therefore, were not factored in further analysis.

One-way ANOVAs determined significant differences in SCP among life stages $(F=155.6 ; \mathrm{df}=6 ; P<0.0001)$, but not sexes $(F=0.743 ; \mathrm{df}=1 ; P=0.395)$. These results complement our field survival observations, suggesting that lab-measured SCPs may approximate field outcomes. A post hoc Tukey-Kramer HSD showed significant differences among life stages (Fig. 2). The SCPs of adults ranged from $-6.85^{\circ} \mathrm{C}$ to $-18.34^{\circ} \mathrm{C}\left(\bar{X}=-10.35^{\circ} \mathrm{C} ; \sigma_{X}=2.54\right)$ and was similar to values recorded from later instar nymphs $\left(-6.09^{\circ} \mathrm{C}\right.$ to $\left.-21.14{ }^{\circ} \mathrm{C}\left(\bar{X}=-11.00^{\circ} \mathrm{C} ; \sigma_{X}=4.92\right)\right)$.

Supercooling points occurred at lower temperatures for eggs and 24-h-old first instars than for adults and late instars, and lower for eggs than first instars (Fig. 2). Murgantia histrionica first instars are nonfeeding (Zahn et al. 2008, Wallingford et al. 2011), and therefore, may not possess enriched levels of ice-nucleating agents as later life stages may since some nucleating agents may be present from food sources (Sømme 1982). First-instar N. viridula absorb atmospheric water, aggregating on their egg mass to resist desiccation, before molting (Hirose et al. 2006); M. histrionica may be similarly adapted. Water absorption may not have an impact on nymph supercooling points, since total water content and SCPs did not correlate in later nymphs and adults.

When M. histrionica eggs masses were subjected to subfreezing conditions, egg mortality (Fig. 3) reflected egg SCP observations, indicating that eggs are likely more cold-hardy than other life stages. Egg cold-hardiness is not uncommon in insects. For instance, Rosales et al. (1994) found similar dramatic differences among life stages of Musca autumnalis De Geer (Diptera: Muscidae), eggs being especially cold hardy. Aphid (Homoptera: Aphididae) eggs are widely known to be cold hardy (Strathdee et al. 1995). In addition, Olson et al. (2013) reported SCPs in Cimex lectularius L. (Hemiptera: Cimicidae), with eggs having the lowest value.

Most reports (Thomas 1915, Paddock 1915, 1918) indicate that adults are the most common stage to overwinter. However, late fall 


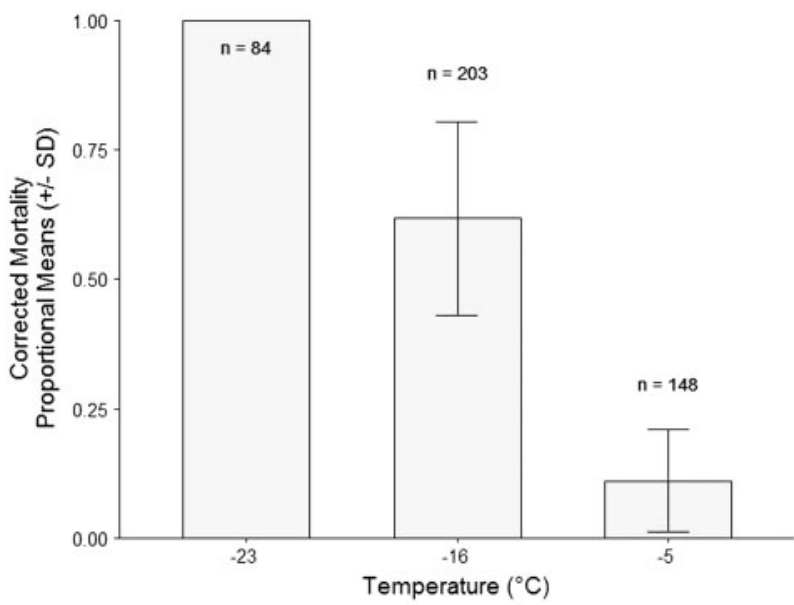

Fig. 3. Mean egg mortality in M. histrionica after simulated exposures to subfreezing temperatures. Egg masses laid within $48 \mathrm{~h}$ introduced by a cooling rate of $\sim 0.16^{\circ} \mathrm{C} \min ^{-1}$ to $-23^{\circ},-16^{\circ}$, and $-5^{\circ} \mathrm{C}$ and held for $30 \mathrm{~min}$, then reacclimated to $20^{\circ} \mathrm{C}$ at $\sim 2.00^{\circ} \mathrm{C} \mathrm{min}^{-1}$. Total hatches tallied over a 20 -d period post cold treatment; mortality was defined by the proportion that did not hatch. Means corrected for control mortality (where 149 of the 171 control eggs successfully hatched) with Abbott's formula, with standard deviations annotated respectively around the means.

reproductive activity is not uncommon in M. histrionica (Sullivan and Brett 1974); therefore, sudden extreme cold weather episodes in the late fall is likely to negatively impact the population. M. histrionica egg age and maternal life history may cause seasonal differences in egg SCP and survivorship. Regardless, the significantly lower SCPs of M. histrionica eggs and first-instar nymphs suggests that during mild winters they are more likely to survive and develop into adults, which can exacerbate pest populations during the following growing seasons.

Cira et al. (2016) found a range of supercooling points in $H$. halys, and documented chill-intolerance as the result of significant differences in mortality at temperatures above their supercooling points. This pentatomid has one to two generations per year in the Mid-Atlantic States, and undergoes reproductive diapause before overwintering (Rice et al. 2014). As a survival strategy, the bugs seek anthropogenic structures, fallen and standing dead trees, and cliff outcroppings to remain buffered against extreme temperature fluctuations during winter months (Lee et al. 2014).

Murgantia histrionica do not seek structures that protect them against subfreezing temperatures as $H$. halys do. Instead we regularly observe $M$. histrionica overwintering nearby host plant communities at the soil surface blanketed with leaf litter and crop residue, or within winter cover crops. Because of their overwintering habitats, supercooling points in M. histrionica were related to field mortality during extreme cold weather events. Results from our 2014 field winter mortality observations $(88 \%$ mortality at $-15.8^{\circ} \mathrm{C}$ ) are consistent with the modeled M. histrionica cumulative SCP distribution (Fig. 4), indicating that SCPs have predictive value for mortality in adults, and presumably early and late stage nymphs since their mean SCP are statistically similar to adults.

Our investigations were limited to Beltsville, MD, and Painter, VA, populations; geographically distinct phenotypes in other climates should be investigated and compared to understand phenotypic plasticity that may accelerate or restrict $M$. histrionica geographic range and abundance (Sgrò et al. 2015). A recent invading pentatomid in the southwestern United States, Bagrada hilaris (Burmeister), is a closely related (Pentatomidae: Pentatominae: Strachiini) brassica specialist native to temperate regions of Africa,

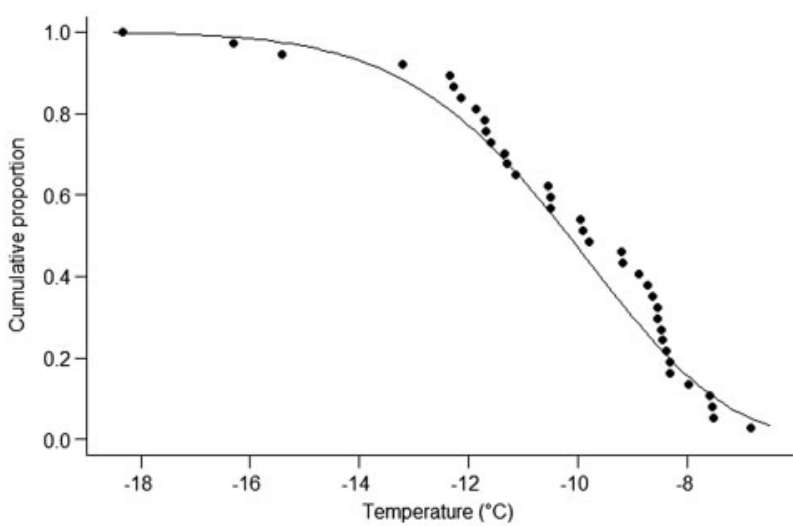

Fig. 4. Cumulative distribution of supercooling points observed for $M$. histrionica adults (black dots), fitted with a predictive curve. Predicted cumulative supercooling points calculated with a gamma distribution (continuous line) based on maximum likelihood parameter estimates with a shape of 19.293612 ( $\mathrm{SE}=4.4474076$ ), and following a rate of 1.863324 ( $\mathrm{SE}=0.4351432$ ) with an AIC of 171.1608.

India, and the Middle East. This species has similar overwintering biology (Singh and Malik 1993) to M. histrionica and could be another noteworthy pentatomid to study in comparison with $M$. histrionica; $B$. hilaris range in the southwestern United States is expanding both eastward and northward (Reed et al. 2013).

Future work on M. histrionica low temperature biology should continue to combine lab and field studies, aimed at investigating the plastic responses that drive genetic variations within fluctuating climates (Sgrò et al. 2015). Since M. histrionica quiescence is dependent on extrinsic cues, fluctuations in temperature during fall and winter months may have an effect on survival even when temperatures are above physiological lower limits described in this paper. Studies investigating specific seasonal acclimation periods, factors related to population origins, and heat-stress effects on winter survival, are needed to better knowledge of microclimates in overwintering habitats of harlequin bug of $M$. histrionica thermal tolerance. Low-molecular weight sugars and other cryoprotectants such as glycerols and inositol were not measured in this study. Seasonal changes in water content and cryoprotectants accumulations in winter versus summer populations may lead to a better understanding of $M$. histrionica cold hardiness and yield better understanding on the specific physiological factors that improve overwintering survival, such as documented in Harmonia axyridis Pallas (Watanabe 2002).

Global climate change is expected to accelerate in the coming decades (Smith et al. 2015), leading to dramatic fluctuation in regional climates. As Limpasuvan et al. (2004) discuss, stratospheric anomalies impose the greatest amount of energy on the circumpolar vortex, which are factors for the prolonged "polar-vortex" episodes we observed in 2014 and 2015 (Frauenfeld and Davis 2003, Francis and Vavrus 2012). Our study related a climate-driven weather anomaly to field survival and low temperature biology laboratory studies in M. histrionica. Future research is needed to understand how to build well suited pest-prediction models to adjust for altered climate patterns (Bale and Hayward 2010).

\section{Acknowledgments}

We are extremely grateful for the numerous dedicated individuals that made this project possible, especially colleagues at USDA-ARS Invasive Insect Biocontrol and Behavior Laboratory who shared valuable $-80^{\circ} \mathrm{C}$ freezer 
space for our supercooling point measurements. We appreciate Robert Venette (University of Minnesota) for his advice in adapting a supercooling point determination protocol for M. histrionica, as well as Brennan Bathauer for enduring extreme cold temperatures during our field studies, and Madeleine Kahle, Sandra Galbert, and Hallie Harriman for providing technical support for our lab tests. Michael Richard Greason (NASA) was key in simulating and computing theoretical cooling rates for our supercooling point determination set up. We thank Lauris McQuoid-Greason for reviewing this paper before submission.

\section{References Cited}

Abbott, W. S. 1925. A method of computing the effectiveness of an insecticide. J. Econ. Entomol. 18: 265-267.

Bale, J. S., and S.A.L. Hayward. 2010. Insect overwintering in a changing climate. J. Exp. Biol. 213: 980-994.

Baust, J. G., and R. R. Rojas. 1985. Review-insect cold hardiness: Facts and fancy. J. Insect Physiol. 31: 755-759.

Bradshaw, W. E. 2010. Insects at not so low temperatures: Climate change in the temperate zone and its biotic consequences, pp. 260-262. In D. L. Denlinger and R. E. Lee (eds.), Low temperature biolology of insects. Cambridge Univeristy Press, New York.

Cabrera Walsh, G., A. S. Dimeglio, A. Khrimian, and D. C. Weber. 2016. Marking and retention of harlequin bug, Murgantia histrionica (Hahn)(Hemiptera: Pentatomidae), on pheromone baited and unbaited plants. J. Pest Sci. 89: 21-29.

Carrillo, M. A., N. Kaliyan, C. A. Cannon, R. V. Morey, and W. F. Wilcke. 2004. A simple method to adjust cooling rates for supercooling point determination. CryoLetters 25: 155-160.

Cira, T. M., R. C. Venette, J. Aigner, T. Kuhar, D. E. Mullins, S. E. Gabbert, and W. D. Hutchison. 2016. Cold tolerance of Halyomorpha halys (Hemiptera: Pentatomidae) across geographic and temporal scales. Environ. Entomol. 45: 484-491.

Delignette-Muller, M. L., C. Dutang, R. Pouillot, and J. B. Denis. 2015. Fitdistrplus: Help to fit of a parametric distribution to non-censored or censored data. Version 1.0-6. (https://cran.r-project.org/web/packages/fitdistr plus/index.html)

Duman, J. G., D. W. Wu, L. Xu, D. Tursman, and T. M. Olsen. 1991. Adaptations of insects to subzero temperatures. Q. Rev. Biol. 66: 387-410.

Elsey, K. D. 1993. Cold tolerance of the southern green stink bug (Heteroptera: Pentatomidae). Environ. Entomol. 22: 567-570.

Francis, J. A., and S. J. Vavrus. 2012. Evidence linking Arctic amplification to extreme weather in mid-latitudes. Geophys. Res. Lett. 39: L06801.

Frauenfeld, O. W., and R. E. Davis. 2003. Northern Hemisphere circumpolar vortex trends and climate change implications. J. Geophysical Res.: Atmospheres 108: 4423.

Hanson, A. A., and R. C. Venette. 2013. Thermocouple design for measuring temperatures of small insects. CryoLetters 34: 261-266.

Hirose, E., A. R. Panizzi, and A. J. Cattelan. 2006. Effect of relative humidity on emergence and on dispersal and regrouping of first instar Nezara viridula (L.)(Hemiptera: Pentatomidae). Neotropical Entomol. 35: 757-761.

Kocin, P. J., A. D. Weiss, and J. J. Wagner. 1988. The great arctic outbreak and east coast blizzard of February 1899. Weather Forecast 3: 305-318.

Lee, R. E. 1991. Principles of insect low temperature tolerance, pp. 17-46. In R. E. Lee D. L. Denlinger. (eds.), Insects at low temperature. Chapman and Hall, New York.

Lee, R. E. 2010. A primer on insect cold-tolerance, pp. 4-6. In, D. L. Denlinger, and R. E. Lee. (eds.), Low Temperature Biology of Insects. Cambridge University Press, New York.

Lee, R. E., and D. L. Denlinger. 2010. Rapid cold-hardening: Ecological significance and underpinning mechanims, pp. 35-36. In, D. L. Denlinger and R. E. Lee (eds.), Low temperature biolology of insects. Cambridge University Press, New York.

Lee, D. H., J. P. Cullum, J. L. Anderson, J. L. Daugherty, L. M. Beckett, and T. C. Leskey. 2014. Characterization of overwintering sites of the invasive brown marmorated stink bug in natural landscapes using human surveyors and detector canines. PLoS ONE 9: e91575.
Leroux, M. 1993. The Mobile Polar High: A new concept explaining present mechanisms of meridional air-mass and energy exchanges and global propagation of palaeoclimatic changes. Glob. Planet. Change 7: 69-93.

Limpasuvan, V., D. W. Thompson, and D. L. Hartmann. 2004. The life cycle of the Northern Hemisphere sudden stratospheric warmings. J. Climate 17: 2584-2596.

Mills, L. J., J. C. Ferguson, and M. Keller. 2006. Cold-hardiness evaluation of grapevine buds and cane tissues. Am. J. Enol. Vitic. 57: 194-200.

Olson, J. F., M. Eaton, S. A. Kells, V. Morin, and C. Wang. 2013. Cold tolerance of bed bugs and practical recommendations for control. J. Econ. Entomol. 106: 2433-2441.

Paddock, F. B. 1915. The harlequin cabbage-bug. Texas Agric. Exp. Stn. Bull. 179: 1-9.

Paddock, F. B. 1918. Studies on the harlequin bug. Texas Agric. Exp. Stn. Bull. 227: 1-65.

R Core Team 2014. R: A language and environment for statistical computing. Vienna, Austria. (http://www.r-project.org/).

Reed, D. A., J. C. Palumbo, T. M. Perring, and C. May. 2013. Bagrada hilaris (Hemiptera: Pentatomidae), an invasive stink bug attacking cole crops in the southwestern United States. J. Integr. Pest Manage 4: 1-7.

Rice, K. B., C. J. Bergh, E. J. Bergmann, D. J. Biddinger, C. Dieckhoff, G. Dively, H. Fraser, T. Gariepy, G. Hamilton, T. Haye, et al. 2014. Biology, ecology, and management of brown marmorated stink bug (Hemiptera: Pentatomidae). J. Integr. Pest Manage. 5: A1-A13.

Rosales, A. L., E. S. Krafsur, and Y. Kim. 1994. Cryobiology of the face fly and house fly (Diptera: Muscidae). J. Med. Entomol. 31: 671-680.

RStudio 2014. Integrated development environment for R, Version 0.98.1102. Boston, MA. (http://www.rstudio.org/).

Salt, R. W. 1961. Principles of insect cold-hardiness. Annu. Rev. Entomol. 6: $55-74$.

Sanderson, D. E. 1908. The influence of minimum temperatures in limiting the northern distribution of insects. J. Econ. Entomol. 1: 245-262.

Saulich, A. K., and D. L. Musolin. 2012. Diapause in the seasonal cycle of stink bugs (Heteroptera, Pentatomidae) from the temperate zone. Entomol. Rev. 92: 1-26.

Sgrò, C. M., J. S. Terblanche, and A. A. Hoffmann. 2015. What can plasticity contribute to insect responses to climate change? Annu. Rev. Entomol. 61: 433-451.

Sinclair, B. J., A. Addo-Bediako, and S. L. Chown. 2003. Climatic variability and the evolution of insect freeze tolerance. Biol. Rev. 78: 181-195.

Singh, H., and V. S. Malik. 1993. Biology of painted bug (Bagrada cruciferarum).Indian J. Agric. Sci. 63: 672-674.

Smith, S. J., J. Edmonds, C. A. Hartin, A. Mundra, and K. Calvin. 2015. Near-term acceleration in the rate of temperature change. Nat. Clim. Change 5: 333-336.

Sømme, L. 1982. Supercooling and winter survival in terrestrial arthropods. Comp. Biochem. Physiol. Part a: Physiol. 73: 519-543.

Strathdee, A. T., G. G. Howling, and J. S. Bale. 1995. Cold hardiness of overwintering aphid eggs. J. Insect Physiol. 41: 653-657.

Sullivan, M. J., and C. H. Brett. 1974. Resistance of commercial crucifers to the harlequin bug in the coastal plain of North Carolina. J. Econ. Entomol. 67: 262-264.

Thomas, W. A. 1915. The cabbage harlequin or calico bug. Bull. S. C. Agric. Exp. Stn. 28:

Venette, R. C., D. J. Kriticos, R. D. Magarey, F. H. Koch, R. H. A. Baker, S. P. Worner, N. N. Gómez Raboteaux, D. W. McKenney, E. J. Dobesberger, D. Yemshanov, et al. 2010. Pest risk maps for invasive alien species: A roadmap for improvement. Bioscience 60: 349-362.

Wallingford, A. K., T. P. Kuhar, P. B. Schultz, and J. H. Freeman. 2011. Harlequin bug biology and pest management in Brassicaceous crops. J. Integr. Pest Manage. 2: H1-H4.

Walker, H. G., and L. D. Anderson. 1933. Report on the control of the harlequin bug, Murgantia histrionica Hahn, with notes on the severity of an outbreak of this insect in 1932. J. Econ. Entomol. 26: 129-135.

Watanabe, M. A. 2002. Cold tolerance and myo-inositol accumulation in overwintering adults of a lady beetle, Harmonia axyridis (Coleoptera: Coccinellidae). Eur. J. Entomol. 99: 5-10.

Zahn, D. K., R. D. Girling, J. S. McElfresh, R. T. Cardé, and J. G. Millar. 2008. Biology and reproductive behavior of Murgantia histrionica (Heteroptera: Pentatomidae). Ann. Entomol. Soc. Am. 101: 215-228. 